\title{
Operational Determination: Math in buildings and math statements about them
}

\author{
by Staale Sinding-Larsen
}

\author{
To the memory of \\ BERNT PETTER ERSTAD, \\ Civil Engineer, The Norwegian \\ Institute of Technology (NTH).
}

For the question of relations between architecture, or more generally, design, and math, there seems to be two schools. As a great light on Roman buildings told me, Borromini's architecture has notbing to do with math. On the other hand, for some of us, it is hard to see how you can bypass the issue; especially if you look at the field as something more than just numerical calculation. One might, as Giordano Bruno did, argue in terms of interrelated magnitudes (SL, Patterns and Programs, 1.4) without codifying anything in numerical or any other formal math format. The main point in the present discussion is that, while architecture and design taken as whole is at least physically attestable, math does not appear always as numbers and on paper or on the machine, but may be an active configuration in the murky depths usually referred to as our mind, without being necessarily explicitly recorded.

\section{Elusive issues}

Given the indeterminate definitory status of both math and architecture - or, more generally: design, the option left us is operational determination; it is our handling an object that gives it a managable identity (above the levels of trivia; SL, Burden, Patterns and Programs, and Bridgman). In the present context, this seems to open up a twofold line of argumentation. The first part goes by two steps. We start out with considering math operations, whether explicit or implicit or potential, and dimensionally scalar, vectorial, differential or integral, or topological. Then we ask what kind of numerical, geometrical or symbolic manipulations can be appplied to design, or lies there already, explicitly or by implication. Whenever the shape can be subjected to math operations or seems to invite math thinking, what sort of procedures, and what kind of cognitive, conceptual and situational or environmental frameworks, can a visual shape call up by virtue of its essential form (a term to be considered presently)? The next step concerns the implications of evaluating these issues together, as a pattern of reciprocal interaction.

The problem picture just outlined is not a static one but shows a process or processes, eluding definite solutions. Some formats can advantagously be analysed in metaphorical terms on an information model (SL, Patterns and programs, 4.3.5, using material from Davis and Olson; see also Inmon). 
So my program aims at nothing more than approaching the probable terms of a framework analysis. What is the methodological significance of such an agenda, how are we to recognize and describe it (I am going to speak of describe and description, to cover also cognitive awareness, epistemological access and recognition)? The matter is further involved by the circumstance that math, and not only geometry, can call forth pictures or visual models; a contingency that is of course much dependent on specific properties. Visualizing in general depends on environmental factors and individual attitudes, inclinations and competences. But images, mental or visual, have often guided enterprises in science and thus also in math (see Holton's and Miller's publications cited in the Bibliography). According to Werner Heisenberg, Niels Bohr, regarding his atom model with its planetary orbits,

\begin{abstract}
believed in his pictures of the atom, less in his own bypothesis about the atomic reality behind them (Es ist also gar nicht so sicher, daß Bohr selbst an die Elektronenbabnen im Atom glaubt. Aber er ist von der Richtigkeit seiner Bilder überzengt) (Heisenberg, 1996, 49).
\end{abstract}

On several levels of abstraction, math and imagery, mental or visual, geometrical, topological or otherwise, interact, dovetail or mutually intefere with one another. It may seem relevant to presume that our deep-set faculty of pictorialization forms a link between math and the experience of visual shapes such as design. Wittgenstein, in his Bemerkungen über die Grundlagen der Mathematik, another of his collections of propositions, offers some considerations in support of this idea . $\mathrm{He}$ is, of course, one would say, aware of the human dimensions accompanying work in and with math. Numbers are, conceptually speaking, figures/images, and arithmetics informs us about their properties. But the difficulty lies in the fact, that the properties represent possibilities. Die Zablen sind Gestalten (ich meine nicht die Zablzeichen) und die Arithmetik teilt uns die Eigenschaften dieser Gestalten mit. Aber die Schwierigkeit ist da, daß diese Eigenschaften der Gestalten M ö g li c b k e e i t e n sind. Und diese Möglichkeiten wieder entpuppen sich als physikalische, oder psychologische, Möglichkeiten... etc. (Wittgenstein, 229f.).

Without venturing to elaborate Wittgenstein's point any more than this, it seems advisable to be aware that much math calls forth imagery, and once this has happened, one is left roaming in the fuzzy landscape into which pictures generally seem take us (SL, Burden).

The process is not reversible, for a picture and the words describing it (on paper or in our brain; often not the same, it would appear), do not point unequivocally back to the number group. In fact, both these media are indeterminate and indefinite with respect to their reference downpour zone. Grasping their import will have us fanning out over a wide configuration space. The famous idea of falsification (due mainly to Popper) can be applied only to numbers handled in regular math 
procedures, isolated, to the extent possible, from the environment. This should mean that propositions in verbal terms cannot be either proved or rejected, except by other verbal expressions: the blind leading the blind.

\section{Shape and form}

A design object must be - and normally will be - subjected to a two-level approach, regarding what we can se directly and what we seem to sense behind it or inside it. Seeing a cupola, we may feel that there is some basic notion or form determining its base curve, a pure circle, and at school we learn that it means $x^{2}+y^{2}=r^{2}$. A similar event can occur when considering tilings and patterns (Grünbaum and Shephard).

Lord and Wilson, in their indispensable book, The mathematical description of shape and form, make a distinction which is relevant for the present discussion. We have chosen the word shape to indicate those aspects of geometrical form which have to do with the external aspect that an object presents to the world. The word form has been reserved to indicate that some aspects of internal structure is also under consideration (from the Preface). Elsewhere I have developed the distinction between system and elaboration when discussing pictiorial programs based on a recordable and well-defined canonical system (SL, Patterns and programs, 1.6, 1.6.1). In the humanities as in the sciences, one should respect the difference between independent and dependent variables; even though the former in this environment will always be a matter of (non-statistical) probability or heuristics.

We seem to be justifed in focusing on the conceptual side, which also, indeed, includes the technical and mathematical aspects. Characteristically, Gregory's book, Mind in Science. A History of Explanations in Psychology and Physics, in his very extensive treatment of machinery, focuses constantly on the conceptual functions.

To say this may sound like laboring the obvious, but further enquiry will show that the idea of concept is tricky enough to require closer inspection (see Putnam for conceptions as a question of abilities rather than properties). For there is also the concomitant aspect that this way of reasoning bridges over to noncommon sense design environments, in computer science, in the virtual world and mathematization of concept lattices (Ganter and Wille). This should mean that the impact of math operations on design must involve also some software environments.

\section{A prototype case}

To lend some more substance to the above points, which touch directly on the distinction shape/form, let us have a look at a sculpture that, with its complex structure of simple forms and with its exposure to public view, shows essential characteristics of buildings: Eduardo Chillida's block sculpture. 


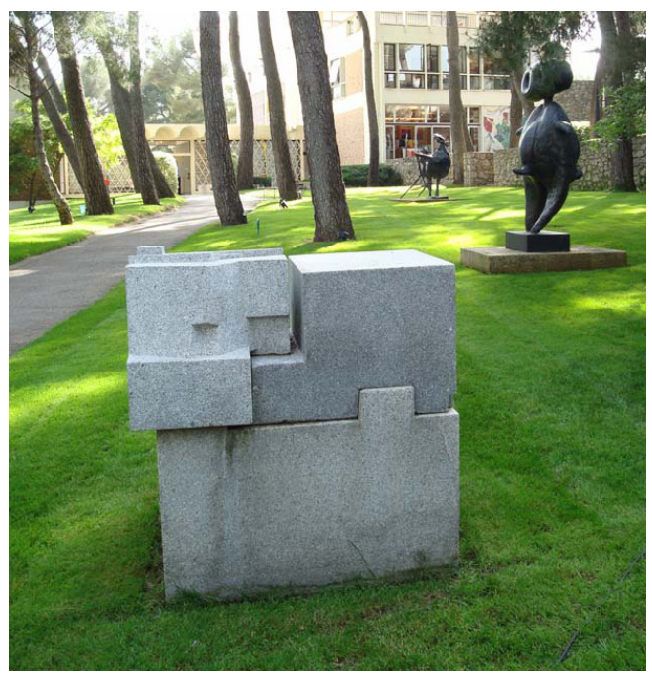

Fig. 1. Eduardo Chillida, Sculpture (Coll. Maeght, St.-Paul-de-Vence). Phot. Liv SindingLarsen.

Simple and composite blocks are bounded by roughly rectangular surfaces that are dovetailed into one another in a pattern which seems to defy direct observation; at least so to many of us. For some of us, again, from observation of this complex shape an expectation may arise to find so to speak inside the configuration some plainly Euclidean squares and rectangles bounding separate simple geometrical figures in unspecified spatial juxtaposition, in other words, a set of forms. This is the kind of dynamic tension which architects and artists, for example Matisse and the German expresionists, exploited. In handling some system such as we find in Chillida's sculpture, we are moving innside the domain of math ideas.

\section{Proportions and ideologies}

Now let us consider some deceptively simple cases of math application. Recording the dimensions of the fourteenth-century Florentine constructions of door and window arches (SL, 1975), a relatively plain proportional formula emerges (computerized documentation), by which the craftsmen could construct the arches and their frames. Simple "recipe" patterns as these were common in Europe, and, according to Paul Booz (in his Die Baumeister der Gothik); served statical as well as formal purposes (see below). These simple data should not be evaluated in isolation but have to be integrated in a large and meaningful system. As they are 
the prominent decoration element on the public and governmental buildings as well as those of the upper class of merchants and bankiers, the design features became symbolic of the sophisticated financial and math culture in the city, but also of the political role of the cited class, which - usually through the guilds, represented the constitutional element of the Florentine state. At the same time, the geometrical order supported and confirmed the tradition of a city and state which considered itself an instantiation of the heritage from ancient Rome (details in SL, 1975). If we started out from any one of these features (here sketchily conveyed), the path along which we might be led back to the arches and their math expressions is just one among numerous alternatives.

In this way, a number applied to a design object is absorbed into it by being processed in the composite image with which it presents itself to the world. Hence, speaking of number applied to design, we have left the range of math, making the number resurface in the composite and indeterminate design terms. Measuring the height of a wall, we are no longer concerned with numbers but with the wall. This little example of a model can be extrapolated to larger or more complex issues. Math ideas or descriptions can be expressed verbally, the speaker (or writer) not necessarily being aware of the numerical equivalent(s) or potentials. Palladio's Quattro libri may be cited as referring to at least one case in which the approximation issue arises, even though he does not say so. In a book tightly packed with measurements - there are numbers all over his drawings, one case is treated verbally in default of a numerical method. One of his ancient vaults in Libro Primo is a volto tondo. Here, we are told (more to the point: his customers, present and prospective, are told, for the architect's treatises were sales catalogs): ... the curve of the vault, the closer it approaches the corners, the rounder it becomes (quanto più s'approssima à gli angoli; tanto più diuenta ritondo). One may risk the guess here that Palladio would have desired to express this variable "roundness" in a number format. His clients, many of whom were business men, would have felt even safer if he had been able to do that. But the required math tools were not as yet available. Giordano Bruno, working with general theory, unhampered by das Unbehagen der Kultur, could opt for a more direct way, to show the argument in a graphic model (Patterns and programs, 1,4).

\section{Borromini's differential curves and manifolds.}

The next group of cases is much more complex. Francesco Borromini introduced curves and surfaces in his buildings which defied contemporary math, while at the same time they represented forms, behind their shapes, that did belong to the formal register which the efforts toward the mature calculus in the initial phase were committed to handle (details in my Patterns and programs).

The most notable architectural case is the transition from wall to cupola in the interior of Sant'Ivo (Fig. 2. For the details, see SL, Patterns, $1.5 \mathrm{ff}$.).

Here, there is a passage from convex wall sections upwards into the cupola, where the surface necessarily assumes concavity. In this fashion, a convex surface is turning continuously, that is, differentially, into a concave one. 


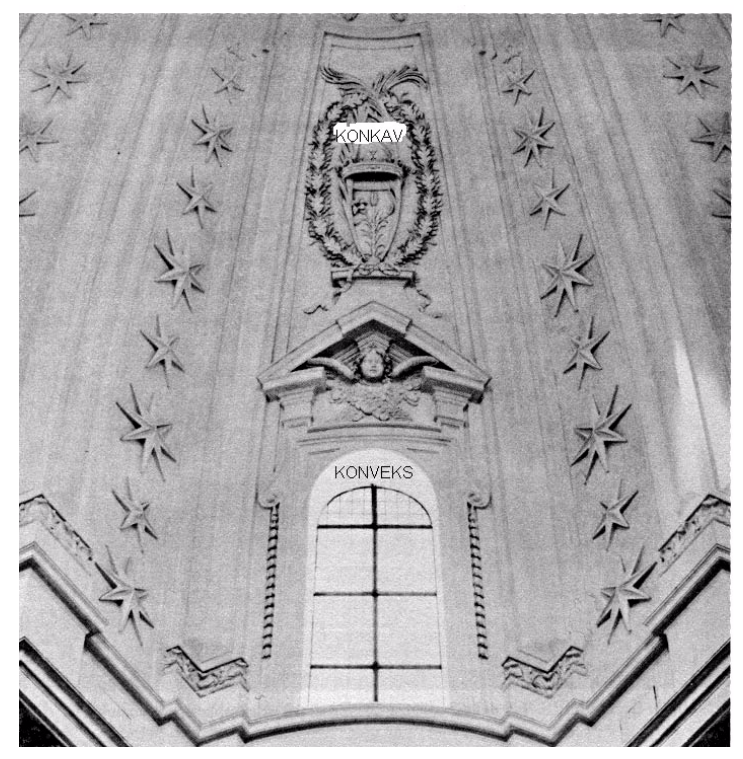

Fig. 2. Sant'Ivo, interior; transition from main body up to the cupola, from convex to concave (in Norwegian but hardly difficult).

There are many equally challenging shapes in Borromini's renovation and partial rebuilding of the Cathedral of Rome, San Giovanni in Laterano; let me cite one of them. On the frame that Borromini designed for an earlier funerary monument to be reinstalled in the partly renovated church (also the work of Borromini), the monument for Cardinal Giulio Acquaviva (Fig. 3), the horizontal element that classically would have been an architrave parallell to the wall system, is bent inwardly so as to convey the impression of an inverted perspective. In fact, the pseudo-architrave may be described as a relatively close approximation to a projection onto a vertical plane of a cosine curve between 0 and $2 \pi$. The element, however, is not closed in one plane, for the trough is gradually bent inwards starting from the end points, the lateral crests, so that it deflects from the vertical front plane to a plane at some 15 degrees to that. Thus the architrave represents a spatial shape of high complexity. 


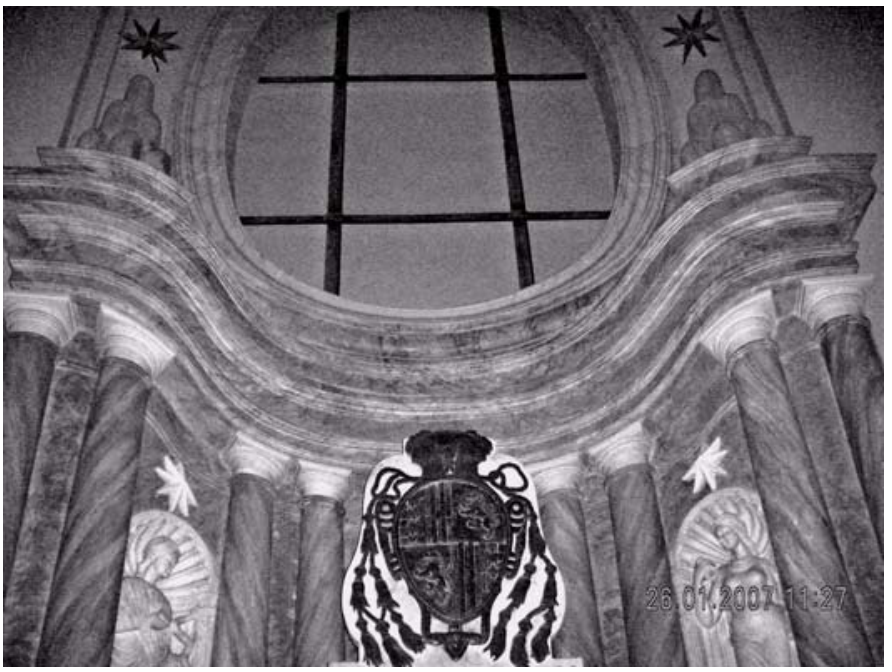

Fig 3, San Giovanni in Laterano, Funerary monument for Cardinal Acquaviva.

Curves of this kind may be labeled differential curves (rather than indefinite, as with Anthony Blunt), for the implication is then that some kind of differential, as was being developed at the time, was required for handling them (Patterns, 3.4 and Subsections). In fact, some of the curves and surfaces to be fully manageable, would require differential geometry, a method not available at the time.

When I speak of differential curves, they should be understood as being embedded in manifold configurations, as the "ovary" shapes in San Carlino, which must be understood in connection with the complex wall structure. Glenn and Littler's Dictionary of mathematics gives the following description (rather than definition) of manifolds: Any entity constructed from a number of enities usually infinite, as a three-dimensional manifold constructed of all points with coordinates $x, y, z$. This is thus an operational procedure rather than a definitory one regarding meaning or significance, telling us how a manifold comes into existence. Taken at the outline level, without entering into the math details, it should be applicable to all architectural forms in curved surfaces regardless of their physical boundaries. Borromini lets us go away without a usable vocabulary or nomenclature except mathematics; even that problematic, seeing that many of his forms were at best approachable in terms of a vast array of experimentation with some point-wise direct hits, in a branch of contemporary mathematics which I label protocalculus (the main subject of my Patterns and programs 
Operational Determination

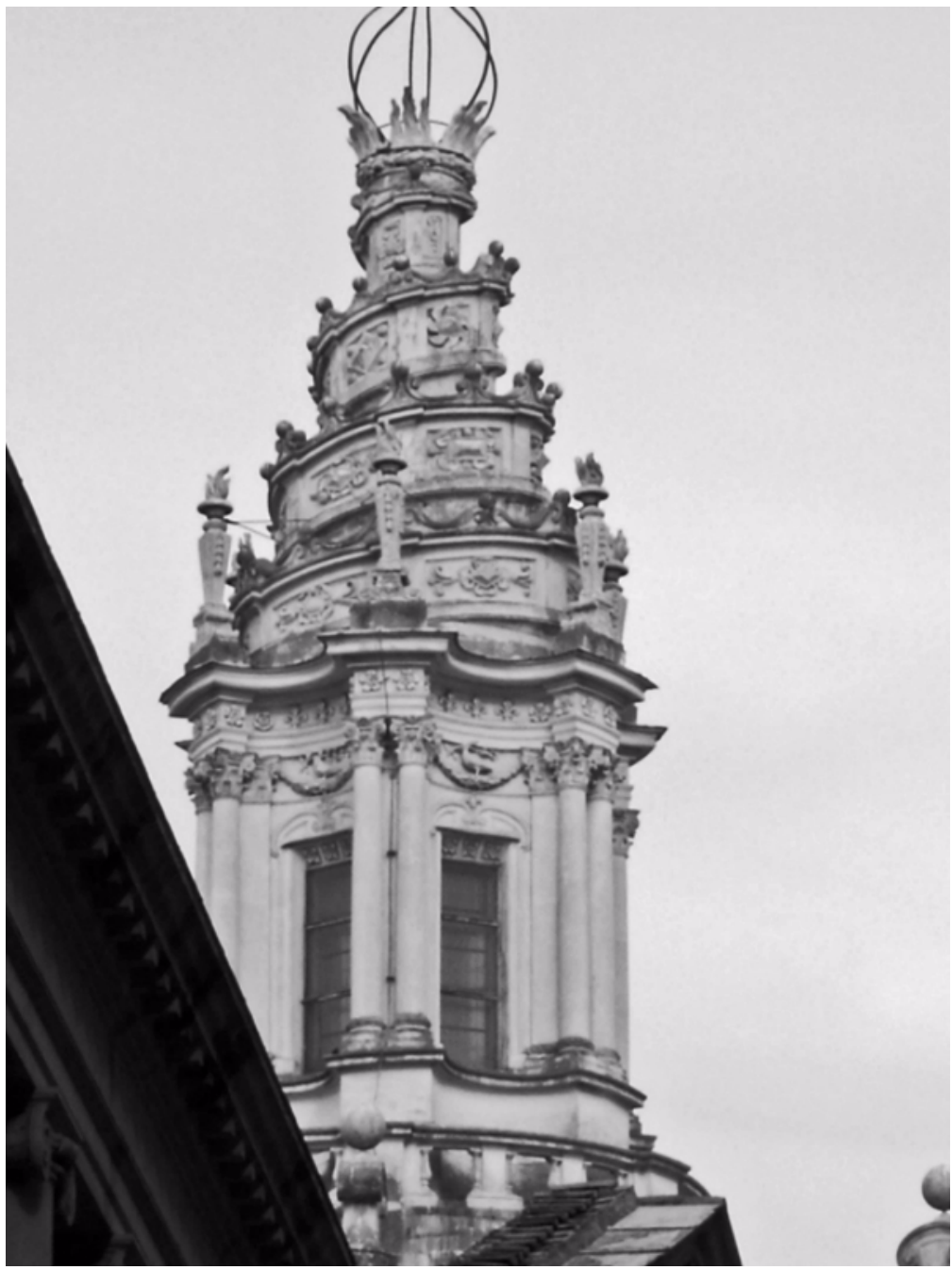

Fig. 4. Rome, Sant'Tvo alla Sapienza, spire seen from the present Via del Teatro Valle. 
in premodern Rome). The Spire on Francesco Borromini's university church Sant'Ivo alla Sapienza in Rome consists essentially of a conical helix with increasing torsion, i.e., the curve getting steeper as it ascends.

The Spire is constructed in travertine with details in stucco and metal. The helical shape is made liturgically relevant by means of a register of religious symbols and images, all of which are standard items in Roman Catholic church contexts - and need not occupy us further here (listed in SL, Burden, 75f.).

Speaking of construction, I do not have in mind the work in masonry and travertine but the abstract configurations that may have been guiding the workmanskip (for a tentative reconstruction of this, see SL, Patterns and programs, 1.9.1). The story supported by documents and reconstructions, is quickly told. Because of the small horizontal area to be occupied by Sant'Ivo (on account of the dimensions of the Sapienza building and the street pattern there), a cupola on top of it would have to be too low to mark off the place on the Roman skyline, with all its paraboloid domes, and too inconspicuous to set off against the many other churches the prestigious building of the Papal University. Some kind of spire or guglia was the only option available. A few blocks away there was (and is) the triumphal column of Marcus Antonius, the philosopher emperor, with its helix running all the way up the trunk. A new inscription set on its base by Sixtus V (who initiated the Sapienza building) calls it a cocblea (a word of Greek origin meaning snail, implicitly also: shell). This name is applied also to the helical Spire.

The world was full of helical shapes but rarely with an increasing torsion.Such a helix, especially a conical one as here, lay far beyond the grasp of contemporary math. Albrecht Dürer had published a drawing to show how a conical helix with increasing torsion could be constructed by raising up numbered verticals from a spiral (a flat curve); but this is constructed not in generative math but by setting up a series of definite points (Sl, Patterns and programs, 1.9).

Today, a general helical curve, in which the torsion and curvature may be variable, is measured in terms of a so-called position vector (Lord and Wilson, 19ff.) This concept and the corresponding technique in differential geometry were not available at the time. It should be noted here, that both Dürer and Torricelli, like everyone else in pre-modern math, also in the protocalculus efforts before the time of Leibniz and Newton, used exclusively geometrical proportions without number calculations, for their configurations. Once erected, the peculiar shape dominated the view not only from the local streets, but even from many far-away points in the city (the Campidoglio, for instance).

To conclude, the torsion increase, which at the time must have been noted as its most challenging feature, was the result of the building process; it is not determined by the basic spiral (to judge from the drawing published by Joseph Connors; see SL, Patterns and programs, 1.9 ). On account of this striking feature, the Spire no 
longer belongs to the category Galilei considered as normal curves (linee semplici) and the crucial element of a helix. The Spire now is merged into the class of differential forms encountered in Borromini's buildings and elsewhere (SL, Patterns and programs 2.2.9). The shapes containing such forms would function as undirected attractors with regard to people receptive to them, in this way intensifying the attempts to cope with complexities. An amanuensis at the very Sapienza university, Galilei's pupil Evangelista Torricelli, worked out the volumetrics of a cylindrical helix, causing even the French to praise him for it (SL, Patterns and programs, 3.2.1); so the idea was in the air.

The design must have challenged math experts and interested people at the university and in its entourage. Math did not belong to the natural sciences, and a show of modernity on the church of the papal university would not call up embarrassing cosmological conundrums (especially after the scandalous canonical rejection of Galilei's observations in 1616). The math factor if evoked would therefore have been cherished by the Church, Patrons of the university without fear of involvement in the cosmological disputes of the day: a harmles sign on a troubled sky. That is to say, math becomes an ideological and political factor; related to this, math can serve as a pledge for correctnes and validity of design: finally, some people will embody math considerations in their attention and reactions without even noticing it, simply bypassing the intermediate steps in a piece of reasonng, a case of expertise in Hubert Dreyfus' analysis (SL, Burden, IV, 2.1 and 9.1).

\section{Grapevine}

A crucial issue arising from our present concern with the relation between math and design is to what extent such conceptual connections would be directly or indirectly present in the minds of contemporaries with a minimum of awareness and knowledge. The question of people's reactions and the working of their "minds" cannot be formulated in any general and analytically reliable terms (Baumgartner and Payr, Benjafield, Callero). The planner outfit and the authorities accepting the Spire idea, will have predicted such reactions on the different levels of contemporary people using the normal combination of normative and explorative prediction (SL, Patterns and programs, 3.1 on Idea generation and planning process). We could set up a probability pseudo-matrix of the range, arguing in the following terms (as I have in fact attempted in SL, Patterns and programs). There must have been talk all around at the Sapienza, the normal community grapevine taking care of that. People directly or indirectly involved came mainly in the following categories: the mathematicians and other math-oriented scholars, the higher clergy, the university scholars in general and, connected with these various categories, circles of men with a higher education who would, to varying degrees, share acquaintance with the scientific aspects of the helical form. In this manner a distribution of competences across the groups would arise.

The kernel of the argumentation concerning the helical thread running up 
the whole shape, is that people with some degree of preparation and awareness of contemporary debates, would see the curve as representing some of the fashionable, hotly discussed, and highly problematic issues in European scholarship in the seventeenth century (carefully introduced in Patterns and programs).

\section{Math and design}

The presence of math, in one form or the other, offers no decisive help in the development of definitions either of architecture nor of design. Math, as a an area of operations, is not easily defined, as Quine pointed out: In Whitehead and Russell's Principia Mathematica we have good evidence that all mathematics is translatable into logic. But this calls for elucidation of three terms: translation, mathematics and logic (Quine, 1980, 80).

Not even categorizations within math are always helpful; thus Eves:. It must be confessed that the classification of bodies of mathematics into the three categories of geometry, algebra, and analysis is largely based on more or less sentimental and traditional grounds, and that the boundaries between the categories are becoming less and less well defined [the position of topology thus remains problematic].

Nevertheless,... most branches of mathematics have ultimate parenthood in either Euclidean geometry, symbolized arithmetic, or the limit processes of the calculus (Eves, 173f.). Furthermore, there exist, undoubtedly, more than one normal system whose use as a logic is feasible, and of these systems one may be more pleasing or more convenient than another, but it cannot be said that one is right and the other wrong (Alonzo Church cited by Eves, 258f.). Lakoff and Núñez offer a matrix for a portrait of mathematics; somewhat excessively colored by adjectives like buman, greatest, extraordinary, and by rather literary argumentation (Lakoff and Núñez, 377ff.).

We are no better off concerning architecture and design. Design, along with architecture, has gained some respectability in engineering and in the relatively new digitial world; as the concept of design is worked out in Winograd's (and others') Bringing design to software, of 1996, at its 11th printing in 2006. A more comprehensive, functionally structured and dynamic sense of design is given by Herbert Simon in his The sciences of the artificial (Chapter 5, 111ff.). I take it that he has arrived at this concept under the impact of two other of his important theories, on the one side, problem solving, and on the other, planning. In this perspective, most human products, mental and physical, can be subsumed and analysed under the model of design procedures. Remaining satisficed (in Simon's term) with everyday notions of both kinds of construction or building structure, we can use - not mathematics but distinctive math operations on them to see what happens.

One problem here is that design is the outcome and reflection of a planning and production process (details in SL, Patterns and programs, 3.1). Karsten Jakobsen, formerly Rector at The Norwegian Institute of technology, speaking of recursive product development, concludes in the following terms (his "five steps" not to be 
taken literally in our context): The process of product development is a recursive process in the sense that a fivestep procedure calls upon itself as the different levels of the product to be designed are uncovered as "chinese boxes". Thus the functional tree cannot be completely specified at the beginning of the product development process, but must be developed gradually as each level is uncovered, and the process of determination of functional requirements (or rather requirement specifications) and of creative thinking (solution generation) are progressing stepwise parallel as a dualism, rather than as a two-step sequence. (Jakobsen, 53). If so, it becomes hard to state what the product really is. This is not a logically stepwise process toward a prefigured goal, solution or result, but a non-linear one by virtue of which the vision or the definition of the expected end result is being construed bit by bit. Anything more complex that just nuts and bolts would be affected by this fuzziness.

The purport of math operations is not always transparent. Lakoff and Nuñez give us a useful reminder. Many of the confusions, enigmas and seeming paradoxes of mathematics arise because conceptual metaphors that are part of mathematics are not recognized as metaphors but are taken as literal (Lakoff and Nuñez, 6).

\section{Math operations}

Let me repeat: analyzing retrospectively, we will hope to cover the essential ingredients and processes involved also in planning, which consists of a preview of the potentials, role and effects of the finished product and consequent prediction. Herbert Simon has often insisted on the role of "hindsight" in learning, planning and prediction, and on recursive processes (e. g. in Simon, 1979), to the extent that prediction works backwards.

When someone among our historical protagonists approached the subject of handling design complexities mathematically or, indeed, took up important features in its episthemological setup, this may have happened in (at least) one of six kinds of operation (or some or all of them):

(1) Working with and/or within the math technique at issue and applying it to the design object; scalar measuring of physical dimensions, resistence and weight, also proportions between elements (such as proportional systems for embellishments or for technical control; as noted by Paul Booz in his Die Baumeister der Gothik; or in Palladio's Quattro libri in which the which the buildings represented in the drawings are completely documented with measurements and proportional relations).

(2) working with other topics which from a cognitive perspective were to prove representative of or "emblematic" for the development of math application to design, such as non-Euclidean curves, surfaces and volumes (e.g. such as those that I call differential, in works e.g. by Borromini; SL, Patterns and programs).

(3) working with some object in the shape format that seems to involve, for some people, not necessarily the creator her/himself, underlying form properties; such as approximate geometries or stereometries (like Chillida's sculpture).

(4) being somehow concerned with the object and accessing, even accepting 
certain characteristics or features in it, without reflecting on the math ingredients indispensable for the object's functioning, a jumping-over several implied steps by virtue of one's expertise (in Hubert Dreyfus' well-known conception of expertise; SL, Patterns and programs, 4.3.6); a common occurence.

(5) working with shapes that have a potentially clear math form while the designer does not consider it, is unaware of it, or is unable to handle it except by "verbal framing-in"; Palladio describing a curve becoming "more rounded", which the then incipient protocaculus (a term in SL, Patterns and programs) would have formalized, at least to some degree.

(6) "Reinterpreting" a flat wall or other neutral surface by means of pictorial decorations that introduce math proportions and shapes (as in Storstein's frescos in Oslo Townhall; see Åse Ødegaard's publication in Norwegian: Et kunstverk blir til - The generation of a work of art, Trondheim 2000).

The questiom is not only which math operations we study or our analysis protagonists employed, but what sort of concepts might accompany the operations and which of them we try to reconstruct with our models.

There is a vast literature, going back to the early middle ages in Europe, which discussed either the application of numbers to artifacts or geometrical visions and configurations applied to them. We have a deceptively simple example in the medieval idas of "meaningful" numbers (twelve columns for the twelve Apostles, etc.). Math operations or more or less conscious math thinking, are rarely unaccompanied by ideological, symbolic or traditional concept, directly or contextually manifest. It would be inadequate to study how the Florentine in the fourteenth century designed their arches on doors and windows without taking into account the power and prestige of calculation (right back to Fibonacci's Liber abaci of 1205) in the business-oriented culture of that city (SL, 1975). Palladio's Quattro libri of 1570 abounds in drawings of buildings of his own invention and from classical Rome, and every detail bears a number: records or instructions for new projects, yes; but also operators informing historians and clients about the historical backing for the proportions, and the ideological and hence often commercial values invested in them.

In the builders' decisions on proportions in a building, their selection of reference points in the edifice - is not unproblematic and may reveal something about conceptions and priorities, especially if rituals are involved. The application of the Golden Section (very frequent) could be looked upon either as a natural, almost in-born, method of achieving order, or as a math expression valued just as such.

Math operations, especially on things in the world, seldom if ever come "alone" or "pure". Doing math can probably occur in isolation when one is training on some specific operations, or teaching them, or evaluating them with respect to manifestations of truth value $(\mathrm{T} / \mathrm{F})$ or, in Kline's words, loss of certainty. In the 
study of larger systems, however, the operations we are performing or studying will arise in the framework of other more or less related math operations or, indeed, in networks of external concepts and processes. The issue will then, normally, be loaded with ideological baggage outside of the normally recognized pale of math operations or even thinking (a Supplement on conceptualization follows at the end of this paper). Such a "baggage" will enter the game from one or both of two quarters: by use procedures, such as applying the operations to design, technically or technologically speaking, or by metaphorical or other associational processes. such as historical references to Roman classical proportions.

The digital paradigmas and also their metaphorical replication have almost always strong capacities for absorbing math statements and operations and also for handling them conceptually, in model format if not directly. The amount of contributions to what with perhaps unjustified simplification I call the digital environment, is enormous. So I shall just cite a few characteristic examples, avoiding the more speculative ones, as they occur in the literature (see the Bibliography): Winograd on Bringing design to software; Bratko on Prolog (ubiquitous recall of conceptualization models); Ganter and Wille on formal concept analysis; Truss with a survey of computer math; the Kirsch volume on the foundations of AI; Bechtel and Abrahamsen on connectionism; Gregory's book on Mind in Science; the Miller volumes on the role and functions of imagery in science; and the great overview in Levine and Rheingold, The cognitive connection. Thought and language in man and machine; Horgan's Undiscovered mind.

Math applied to architecture, or design generally speaking, should be considered as a recording or an instruction concerning metrics and the technical aspects, but also a statement about the subject. The ubiquitous numbers on Palladio's drawing in his Quattro libri (1570) certainly pretend to show how to construct correctly but at the same time to furnish his old and his prospective clients (SL. Patterns, 1.5.2) with ideological significance for their buildings. Serlio in his book (1548) presents a great choice of designs to choose from if one wants to build "classically": a Sears and Roebuck sales catalog avant la lettre (SL, 1978, section The selling of an idea). Written statements by the architects themselves were also written with some purpose not always stated: in support of personal prestige and of marketing the design ideas and prototypes. Especially after the architects had become "humanists", some authorship was expected from them, and they had to play the role as "learned" men, demonstrating their status with comments at least as a garnishing on cakes already out of the oven. In some sense math applications can be compared to written statements about the matter on hand. For this Roy T. Eriksen's expert analyses of architectural writings should be consulted (two examples: Eriksen 2004 and 2006).

Mathematics applied to buildings, then, should be evaluated both for the 
use to which it is being put, but also for its role in stating something about the shapes and forms. Are these clear alternatives? No. Regarding the divide between use and mention, the meta issue in Nagel and Newman's stimulating booklet on Gödel's Proof. I seem to remember that Douglas Hofstadter somewhere (in his Gödel, Escher, Bach, or his more recent book about himself as a Strange loop), affirmed that a statement about number theory is number theory, so that the dichotomy vanishes behind converging functions. It may seem tempting, then, to say that any verbal or math statement applied to design plays this double role.

\section{Generative analysis}

The heuristic or experimental theory directing my work, is that the analysis process, which is the method, the formulation and implementation of smaller or bigger relevant projects, produces the object on hand (bistorical or contemporary) and sends it back to us more or less ready for analytical use (SL, Burden, 184ff.). I have already introduced the paradigm under the name of Operational determination. This is achieved by attributing probable values to the situations and contexts considered relevant, attributions in their turn supported by sub-theories. The idea is not an original one. In support, I may cite Philip Kitcher in his The nature of mathematical knowledge. Kitcher discusses the case of a small child playing with blocks on the floor, thus learning the meanings of 'set', 'number', 'addition' and to accept basic truths of arithmetic by engangng in activities in collecting and segregating. Rather than interpreting these activities as an avenue to knowledge of abstract objects, we can think of the rudimentary arithmetical truths as true in virtue of the operations themselves. On this basis, Kitcher argues that arithmetic describes those structural features of the world in virtue of which we are able to segregate and recombine objects: the operations of segregation and recombination bring about the manifestation of underlying dispositional traits (Kitcher, 107f.).

Obviously, such a "determination" is - to repeat - a process and rarely a final decision. This program affects the relationship between design and mathematics in the sense that applying math to some shape, involves more than just the calculatory, technical and dimensional issues, for the handling unavoidably calls forth and activizes not only features in our mental baggage but also situational and environmental ones. Working out an issue in a systems mode, if adequately struc-tured, can obviate the need for "explanations" of a causal nature, since, as Radnitzsy notes, explanation is a by-product of systemization (Radnitzky, II, 102). Furthermore, operational determination is a process in which decisions on defining stages are arbitrary, so that no stage can be considered terminal except for motivations of convenience. No final dénouement.

Staale Sinding-Larsen

Emeritus, NTNU 


\section{Bibliography}

Baumgartner, P., and Payr, S., Speaking minds. Interviews with twenty eminent cognitive scientists, Princeton (NJ), 1996.

Benjafield, J. G., Cognition, Englewood Cliffs (NJ) 1992..

Bridgman, P., The operational character of scientific concepts, 57 - 69, in Boyd, R.,

Gasper, Ph., and Trout, J. D., The philosophy of science, Cambridge (MA), 1991.

Callero, P. L., Toward a sociology of cognition, in Howard, J. A., and Callero, P. L. (eds), The self-society dynamic, Cambridge 1991, 43 - 54.

Davis, G. G., and Olson, M. H., Management information systems. Conceptual foundations, 2 ed., New York 1985; paperback 1996.

Downs, R. M., Personal constructions of personal construct theory, in Moore and Gollege, Environmental knowing, pp. 72 - 87.

Eriksen, R. T, Topografia e prospettiva: architettura retorica, Memorie / Acc.Naz. di Modena, 2004, 541560.

Eriksen, R. T, Alberti, Manetti, and Quattrocento aesthetics, ed. Eriksen and Tschudi, Ashes to ashes, Art in Rome between humanism and maniera, Rome 2006.

Eves, H., Foundations and fundamental concepts of mathematics, 3rd ed., Mineola (NY), 1990.

Ganter, B., and Wille, R., Formal concept analysis. Mathematical foundations, Berlin 1999.

Geen, R. G., Human motivation. A social psychological approach, Belmont (CA) 1995.

Gregory, R. L., Mind in Science. A History of Explanations in Psychology and Physics, Harmondsworth, 1984 (originally London 1981, reprint 1988).

Grünbaum, B, and Shephard, G. C., Tilings and patterns, New York 1987.

Heisenberg, W., Der Teil und das Ganze. Gespräche im Umkreis der Atomphysik, Munich 1969.

Holton, G. Thematic origins of scientific thought. Kepler to Einstein, rev.ed., Cambridge (MA). 1988.

Horgan, J., The Undiscovered Mind. How the human brain defies replication, medication, and explanation, New York 1999.

Inmon, W. H., Data architecture. The information paradgm, Wellesley (MA, 1992.

Jakonbsen, K. (ed)., Modern design princiles, Trondheim 1988.

Kitcher, Ph., The nature of mathematical knowledge, New York 1984.

Lakoff, G., and Núñez, R. E., Where mathematics come from. How the embodied mind brings mathematics into being, New York 2000.

Lord, E. A. and Wilson, C. B., The mathemaical description of shape and form, repr.

New York 1986.

Miller, A. I., Imagery in scientific thought, Cambridge (MA) 1986, repr. 1987..

Miller, A. I., Imagery and creativity in Science and art, New York 1996.

Putnam, H. The meaning of meaning, in Mind, language and reality. Cambridge 1975, 
pp. 223 - 227

Quine, W. V., From a logical point of view, Nine logico-philosobical essays, 2nd. revised ed., Cambridge (MA) 1980.

Radnitzky, G., Contemporary schools of metascience, I, II, Göteborg 1968, reprint 1970.

Simon, H. A., Models of thought, New Haven (CT) 1979.

Simon, H. A., The Sciences of the Artificial, 3rd. ed., Cambridge (MA) 1996.

Sinding-Larsen, S., Some finctional and iconographical aspects of the centralized church in the Italian Renaisance, Ist. rom. Nor., Acta, II, 1965, 203 - 252.

Sinding-Larsen, S., A tale of two cities. Florentine and Roman visual context for fifteenthcentury palaces, in Institutum romanum Norvegiae, Acta, Vol.VI, 1975, pp. 163 - 212.

Sinding-Larsern, S., The Laurenziana vestibule as a functional solution, Ist. rom. Nor., Acta,VIII, 1978, pp. 213 - 222. Reprint in Wallace, William E, Michelangelo. Selected scholarship, New York 1998

Sinding-Larsen, S., The burden of the ceremony master. Image and action in San Marco, Venice, and an Islamic mosque, Rome 2000. Review by Ruth Simon/ Schilling, Institut für Geschichtswissenschaften, Humboldt-Universität, Berlin: http:/ / www.h-net.org $/$ reviews $/$ showrev.cgi?path $=91381022723569$.

Sinding-Larsen, S., Patterns and programs in premodern Rome, Shape, form and message systems: an open-source approach = http://ntnu.no/bht/arkitekturhistorie, NTNU publication, 2010.

Sinding-Larsen, S., Working with pictures in elaborated systems, in Jaritz, G. (ed.), Image, ritual and daily life, Institut für Realienkunde des Mittelalters und der frühen Neuzeit, Austrian Academy of Sciences, forthcoming.

Torricelli, Evangelista, Opera geometrica Evangelistae Torricelli, Florence 1644. I, i. 223ff.: De dimensione cochleae .

Winograd, T. (ed.), Bringing design to software, Boston (MA) 1996, eleven printings up to 2006.

Wittgenstein, L., Bemerkungen über die Grundlagen der Mathematik, Werksausgabe Band 6, ed. Anscombe, Rhees and Von Wright, Frankfurt a/M 1984. 